University of Nebraska - Lincoln

DigitalCommons@University of Nebraska - Lincoln

1987

\title{
Quinoline Sorption on Na-Montmorillonite: Contributions of the Protonated and Neutral Species
}

\author{
Calvin C. Ainsworth \\ Pacific Northwest National Laboratory \\ John M. Zachara \\ Pacific Northwest National Laboratory, john.zachara@pnl.gov \\ Ron L. Schmidt \\ Pacific Northwest National Laboratory
}

Follow this and additional works at: https://digitalcommons.unl.edu/usdoepub

Part of the Bioresource and Agricultural Engineering Commons

Ainsworth, Calvin C.; Zachara, John M.; and Schmidt, Ron L., "Quinoline Sorption on Na-Montmorillonite: Contributions of the Protonated and Neutral Species" (1987). US Department of Energy Publications. 191. https://digitalcommons.unl.edu/usdoepub/191

This Article is brought to you for free and open access by the U.S. Department of Energy at DigitalCommons@University of Nebraska - Lincoln. It has been accepted for inclusion in US Department of Energy Publications by an authorized administrator of DigitalCommons@University of Nebraska - Lincoln. 


\title{
QUINOLINE SORPTION ON Na-MONTMORILLONITE: CONTRIBUTIONS OF THE PROTONATED AND NEUTRAL SPECIES
}

\author{
Calvin C. Ainsworth, John M. Zachara, and Ron L. Schmidt \\ Battelle, Pacific Northwest Laboratories, P.O. Box 999 \\ Richland, Washington 99352
}

\begin{abstract}
Dilute aqueous solutions of quinoline were contacted with Na-montmorillonite to elucidate the sorption process of the neutral and protonated species. Sorption occurs via a combination of ion exchange and molecular adsorption and yields S-type isotherms. Exchange between the quinolinium ion $\left(\mathrm{QH}^{+}\right)$and $\mathrm{Na}$ can be described by means of Vanselow selectivity coefficients and a thermodynamic exchange constant $\left(\mathrm{K}_{\mathrm{ex}}\right)$. Due to the apparent adsorption of the neutral species at high mole fractions $(x)$ of the solid phase, the thermodynamic standard state was defined as 0.5 mole fraction. The selectivity at $\mathrm{pH} \sim 4.95$ of the $\mathrm{QH}^{+}$species over $\mathrm{Na}$ (at $\mathrm{X}_{\mathrm{QH}^{+}}=0.5$ ) was determined to be $\mathrm{K}_{\mathrm{v}}=340$. At $\mathrm{pH} \geq 5.5$ surface mole fractions of 0.5 could not be obtained without adsorption of the neutral species. This study suggests that at dilute solution concentrations quinoline is sorbed preferentially as the cation even at $\mathrm{pHs} \gg \mathrm{pK}_{\mathrm{a}}$. A critical surface-solution concentration is apparently necessary for adsorption of the neutral species.
\end{abstract}

Key Words-Adsorption, Cation exchange, Montmorillonite, Quinoline, Vanselow selectivity.

\section{INTRODUCTION}

Although the importance of cation exchange in the adsorption of quinoline and other ionizable aromatic bases in soil and subsurface materials has been established (Zierath et al., 1980; Zachara et al., 1986; Moreale and van Bladel, 1976), little quantitative information exists on the nature of the exchange process. Doehler and Young (1961) found a decrease in quinoline sorption on various clay minerals with increasing $\mathrm{pH}$ and ionic strength. Helmy et al. (1983), expanding on the work of Doehler and Young, observed maximum sorption at about $\mathrm{pH} 6$ on both phyllosilicates and oxides, about one $\mathrm{pH}$ unit $>\mathrm{pK}_{\mathrm{a}}(4.92)$ for quinoline. Both of these studies concluded that the cationic and molecular forms of quinoline were adsorbed. The authors were unable, however, to quantify the contributions of the different species (neutral, protonated) or to determine the selectivity of the exchange process. Sorption studies of purines, pyrimidines, and nucleosides on montmorillonite and illite also point to the importance of cation exchange, and Lailach et al. (1968a, 1968b) and Thompson and Brindley (1969) demonstrated that the $\mathrm{pH}$ of the bulk solution at maximum sorption is related to the $\mathrm{pK}_{\mathrm{a}}$ of the adsorbate. Exchange data for ionizable s-triazine herbicides on Ca-H-humic acid (Gilmour and Coleman, 1971) demonstrated the controlling effect of compound ionization, the importance of the ionization fraction, and the strong selectivity of the sorbent for the univalent organic cation over $\mathrm{Ca}^{2+}\left(\mathrm{K}_{\mathrm{ex}}=18-60\right)$.

The exchange of fully ionized organic cations has been investigated on a variety of organic and inorganic adsorbents, and the magnitude of the determined selectivity coefficients and the exchange constants de- scribing the reaction both point to high stability of the surface complex. This stabilization may derive from a combination of electrostatic, van der Waals, or entropic forces. Grim et al. (1947) reported the stoichiometric replacement of $\mathrm{K}^{+}$by $\mathrm{n}$-butylammonium ions on $\mathrm{K}^{+}$-saturated montmorillonite and the sorption of $\mathrm{n}$-dodecylammonium ions to levels exceeding the cation-exchange capacity. Selectivity coefficients for exchange between mono-, di-, tri-, and tetraalkylammonium ions and sodium on montmorillonite increase with carbon substitution, suggesting free energy contributions from van der Waals forces (Cowen and White, 1958) or entropy gains (Vansant and Uytterhoeven, 1972). The aromatic $\mathrm{N}$-containing cations paraquat and diquat are selectively exchanged over most monovalent and divalent cations by soil clays (Dixon et al., 1970; Philen et al., 1970; Weed and Weber, 1969). Paraquat is also taken up on soil organic materials by ion exchange (Burns et al., 1973), but the selectivity for the organic cation was found to be less than that observed for smectites.

Ionizable aromatic compounds are important environmental contaminants and ambiguities exist regarding their behavior in soil and ground-water environments. In light of these considerations, the present study was undertaken to probe the exchange and molecular adsorption behavior of quinoline over a wide range of $\mathrm{pH}$ and aqueous concentration using a wellcharacterized, charged adsorbent. Sodium-saturated montmorillonite was used as the exchanger-adsorbent to investigate the hypothesized homovalent exchange process. Sorption and exchange isotherms measured under controlled $\mathrm{pH}$ conditions were used to show the wide $\mathrm{pH}$ and concentration region in which exchange 
predominates and the conditions under which molecular adsorption becomes important. A thermodynamic exchange constant was calculated and the mechanism of quinoline interaction with the smectite surface was investigated.

\section{MATERIALS AND METHODS}

\section{Compound purity}

Quinoline (99\% purity, Aldrich Co.) was used without further purification. Radiolabeled ${ }^{14} \mathrm{C}$-quinoline was custom synthesized (Pathfinders Laboratories) and further purified by liquid chromatography (Waters Associates, C- 18 column, $25 \mathrm{~cm} \times 3.9 \mathrm{~mm}$ ) and a $40 \%$ acetonitrile $/ 60 \%$ citrate buffer $(0.05 \mathrm{M}, 1: 1 \mathrm{Na}$-citrate : citric acid). The peak corresponding to quinoline was collected, partitioned into hexane, and back-extracted in $0.05 \mathrm{~N} \mathrm{HCl}$.

\section{$\mathrm{Na}$-montmorillonite}

A bulk sample of montmorillonite (SWy-1, Crook County, Wyoming) was obtained from the Source Clays Repository of The Clay Minerals Society for use in this study. The clay was purified and prepared in the sodium form according to the procedure employed by Sposito et al. (1981); Na was determined by inductively coupled argon-plasma spectroscopy (ICP); $\mathrm{ClO}_{4}$ was determined by ion chromatography (IC). The prepared clay suspension was stored in $0.1 \mathrm{M} \mathrm{NaClO}_{4}$ at about pH 5.5.

\section{Sorption experiments}

Batch exchange studies. Exchange studies were conducted at $25 \pm 0.5^{\circ} \mathrm{C}$ in $200-\mathrm{ml}$ Corex (Corning Glass Works) tubes containing a montmorillonite suspension of about $1 \mathrm{~g} / \mathrm{kg}$ in $0.1 \mathrm{M} \mathrm{NaClO}_{4}$. Nine quinoline concentrations (in triplicate) were used ranging from $\sim 5 \times$ $10^{-4}$ to $\sim 4 \times 10^{-7} \mathrm{M}$. The working clay suspension for each concentration of quinoline was produced by adding about $40 \mathrm{~g}$ of the stock suspension, $0.01 \mathrm{M}$ $\mathrm{NaClO}_{4}$, and deionized $\mathrm{H}_{2} \mathrm{O}$ to a 1-liter bottle to yield $780 \mathrm{~g}$ of suspension at $\sim 0.01 \mathrm{M} \mathrm{NaClO}_{4}$. The suspension was allowed to equilibrate for $24 \mathrm{hr}$. After the equilibration period, an appropriate mass of quinoline and ${ }^{14} \mathrm{C}$-quinoline was added to the suspension and mixed, and two aliquots were removed for $\mathrm{ClO}_{4}$ determination (IC). The $\mathrm{pH}$ was adjusted to 4.9 , and 3 , $120-\mathrm{ml}$ aliquots were removed to Corex bottles. The bottles were capped and shaken for $24 \mathrm{hr}$. The bottles were then weighed and centrifuged, and the supernatant was removed. The bottles and clay plug were weighed, $50 \mathrm{ml}$ of $0.1 \mathrm{M} \mathrm{NH}_{4} \mathrm{OAc}$ was added, and the mixture was agitated for $24 \mathrm{hr}$. This procedure was repeated three times using the $\mathrm{NH}_{4} \mathrm{OAc}$ at $\mathrm{pH} 10$ for the third extraction. All solutions were analyzed for ${ }^{14} \mathrm{C}$-quinoline by liquid scintillation and for $\mathrm{Na}$ by ICP. Occluded volumes and the sorbed concentrations were determined by mass difference; quinoline concentrations were spot checked by direct analysis by liquid chromatography. The total adsorbed charge was calculated by the method of Sposito et al. (1981).

Quinoline sorption. A titration-equilibration technique was employed using a Wheaton Celstir double-sidearm, water-jacketed flask and a Radiometer Copenhagen $\mathrm{pH}$ meter equipped with titrator and autoburette. The temperature was maintained at $25 \pm 0.2^{\circ} \mathrm{C}$. About $400 \mathrm{~g}$ of $0.01 \mathrm{M} \mathrm{NaClO}_{4}$ was added to the flask and degassed overnight with $\mathrm{N}_{2}$. Varying masses of quinoline (hot and cold) were added depending upon the initial concentration desired $\left(\sim 6 \times 10^{-4}\right.$ to $1 \times$ $10^{-6} \mathrm{M}$ ). The $\mathrm{pH}$ was adjusted to 8.0 with $0.11 \mathrm{M}$ $\mathrm{NaOH}$. At this point stock clay suspension was added to yield about $7.25 \times 10^{-4} \mathrm{~g}$ clay/g suspension. The addition of the clay caused the $\mathrm{pH}$ to decrease by $\sim 0.3$ unit. The suspension was titrated to $\mathrm{pH} 8.0$ and held there for $4 \mathrm{hr}$ by additions of $0.114 \mathrm{M} \mathrm{HClO}_{4}$. Three aliquots $(5 \mathrm{ml}$ each) were removed, and the clay and aqueous phases were separated via centrifugation. ${ }^{14} \mathrm{C}$-quinoline was determined by liquid scintillation; $\mathrm{Na}$ was determined by ICP. The $\mathrm{pH}$ was reduced to 7.5 by slow addition of $0.114 \mathrm{M} \mathrm{HClO}_{4}$ and held at that $\mathrm{pH}$ as previously described for $4 \mathrm{hr}$. Samples were again removed and analyzed for $\mathrm{Na}$ and quinoline. The pH was similarly adjusted to 6.5 and 5.5 , with quinoline, $\mathrm{Na}$, and hydrogen consumption determined at all pHs. The clay suspensions were titrated without quinoline, and the degassed electrolyte solution was titrated as blanks to determine the hydrogen consumption background. No attempt was made to determine the exchanger composition directly. The net cumulative sorption of quinoline and the $\mathrm{H}^{+}$consumption for sorption at $\mathrm{pH} 7.5,6.5$, and 5.5 were calculated by summing the appropriate data from previous $\mathrm{pH}$ levels and correcting for the mass removed for sampling and blanks.

Quinoline sorption rate. The time required to obtain a steady-state aqueous quinoline concentration and cessation of hydrogen consumption was determined using the titration-equilibration technique employed in the above sorption experiments. A suspension of $0.75 \mathrm{~g}$ clay/ $\mathrm{kg}$ suspension in $0.01 \mathrm{M} \mathrm{NaClO}_{4}$ and $6 \times 10^{-4} \mathrm{M}$ quinoline tagged with ${ }^{14} \mathrm{C}$ was maintained at $\mathrm{pH} 5.5$ using a pH meter and autotitrator. The quinoline solution concentration was monitored by timed sampling and determination of the aqueous ${ }^{14} \mathrm{C}$-quinoline activity over a period of $560 \mathrm{~min}$. This process was repeated at $\mathrm{pH} 6.5$ and 7.5 .

Cation-exchange capacity. The cation-exchange capacity of each stock clay suspension used was determined by ${ }^{22} \mathrm{Na}$ isotopic dilution (Babcock and Schulz, 1970), using a background electrolyte of $0.01 \mathrm{M} \mathrm{NaClO}_{4}$. 


\section{RESULTS AND DISCUSSION}

\section{Influence of time}

The time required to obtain a steady-state concentration of quinoline and the cessation of hydrogen consumption varied with $\mathrm{pH}$; as $\mathrm{pH}$ increased, time to steady state increased. The sorption reaction reached equilibrium in about $200 \mathrm{~min}$ at $\mathrm{pH} 7.5$, in slightly less time at $\mathrm{pH} \mathrm{6.5,} \mathrm{and} \mathrm{in} \mathrm{about} 100 \mathrm{~min}$ at $\mathrm{pH}$ 5.5. These results agree well with those of Doehler and Young (1961) and Helmy et al. (1983).

\section{Sorption isotherms}

The quinoline sorption data on Na-montmorillonite at $\mathrm{pH} 7.5,6.5$, and 5.5 can be described by a power function:

$$
\mathrm{S}=\mathrm{aC}_{\mathrm{e}}^{\mathrm{b}},
$$

where $\mathrm{a}$ and $\mathrm{b}$ are constants specific to $\mathrm{pH}, \mathrm{S}$ is the number of micromoles of quinoline sorbed per gram of clay, and $\mathrm{C}_{\mathrm{e}}$ is the number of micromoles of quinoline per kilogram of solution. The correlation coefficient $\left(\mathrm{r}^{2}\right)$ for the above function, however, deteriorates with increasing $\mathrm{pH}$ (Table 1). The reason for this erosion of fit to the power function model is evident from the log-log plot of the data in Figure 1. Each pH isotherm shows a distinct break in slope at the higher concentrations, which becomes more severe with increasing $\mathrm{pH}$.

By regressing the upper and lower portions of each curve separately, good fits were obtained to the linear form of the power function $\left(\log S=\log a+b \log C_{e}\right)$. The constants and linear correlation coefficients are presented in Table 1 along with the coordinates denoting the intersection of the related curves. The isotherms at lower equilibrium concentrations are similar in slope (i.e., roughly parallel), with a slope near unity. The isotherm segments at higher concentrations, however, have a steeper slope than their lower-concentration counterparts: $1.62,1.90$, and 2.36 for $\mathrm{pH} 5.5,6.5$, and 7.5 , respectively. The slopes of the higher concentration isotherms (log-log form) increase markedly with increasing $\mathrm{pH}$. Isotherms having this general shape are typically referred to as S-type isotherms.

In certain instances, especially in the adsorption of organic compounds, the S-type isotherm is due to co-

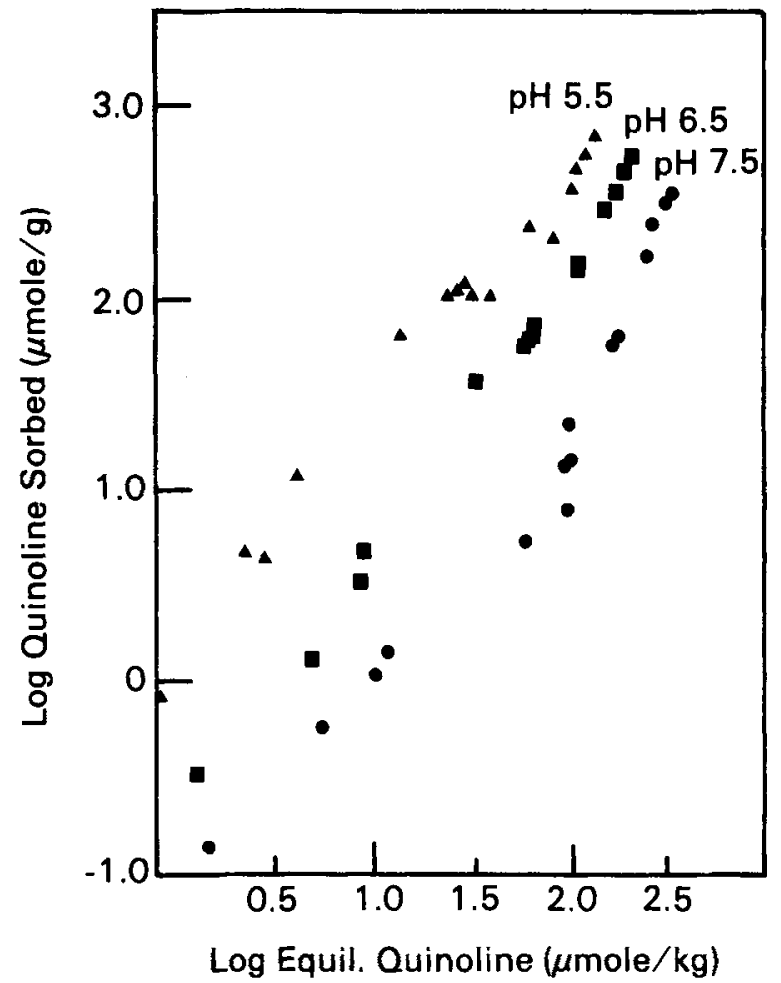

Figure 1. Quinoline sorption on Na-montmorillonite at $\mathrm{pH}$ $7.5,6.5$, and 5.5 over the initial concentration range of $6.09 \times$ $10^{-4}$ to $1.27 \times 10^{-6} \mathrm{M}$.

operative interactions among sorbed organic species, stabilizing the sorbate and enhancing the affinity of the surface for the sorbate (Sposito, 1984, p. 116). Additionally, S-type isotherms may indicate clustering of the sorbate rather than random surface mixing (Sposito, 1981, p. 134). Similar S-type convex curves for quinoline sorption were reported by Doehler and Young (1961) for quinoline sorption on illite and montmorillonite. The magnitude of sorption was influenced by the nature of the saturating cation $(\mathrm{Na}$ and $\mathrm{Ca}), \mathrm{pH}$ (6.5 and 7.5), and salinity. In contrast, Helmy et al. (1983) found quinoline sorption on Na-montmorillonite to yield $\mathrm{H}$-type isotherms, the magnitude being influenced by the nature of the saturating cation $(\mathrm{Na}, \mathrm{Ca}$, $\mathrm{K}$, and $\left.\mathrm{NH}_{4}\right)$ and $\mathrm{pH}(6.7$ and 10.3).

Table 1. Regression constants for quinoline sorption on Na-montmorillonite.

\begin{tabular}{|c|c|c|c|c|c|c|c|c|c|c|c|c|}
\hline \multirow[b]{3}{*}{$\mathrm{pH}$} & & & & \multicolumn{9}{|c|}{$\log S=\log a+b \log C$} \\
\hline & \multicolumn{3}{|c|}{$\mathrm{S}=\mathrm{aC}_{\mathrm{c}}{ }^{\mathrm{b}}$} & \multicolumn{4}{|c|}{ Lower curve } & \multicolumn{4}{|c|}{ Higher curve } & \multirow{2}{*}{$\begin{array}{c}\text { Intersection } \\
\quad(X, Y)\end{array}$} \\
\hline & $a^{1}$ & $\mathrm{~b}$ & $\mathrm{r}^{2}$ & $\mathbf{N}$ & $a^{1}$ & b & $r^{2}$ & $\mathbf{N}$ & $a^{\prime}$ & $\mathrm{b}$ & $\mathrm{r}^{2}$ & \\
\hline 5.5 & 22.9 & 1.18 & .983 & 11 & 0.39 & 1.12 & .967 & 4 & -0.62 & 1.62 & .996 & $(2.0,2.64)$ \\
\hline 6.5 & 89.1 & 1.45 & .981 & 9 & -0.58 & 1.33 & .992 & 6 & -1.69 & 1.90 & .995 & $(1.96,2.04)$ \\
\hline 7.5 & 13.4 & 1.42 & .936 & 8 & -0.99 & 1.088 & .987 & 7 & -3.43 & 2.36 & .967 & $(1.93,1.11)$ \\
\hline
\end{tabular}

\footnotetext{
${ }^{1}$ Units are ( $\mu$ mole ${ }^{1-\mathrm{N}} / \mathrm{g}$ clay) $\mathrm{kg}^{\mathrm{N}}{ }_{\text {sol. }}$.
} 


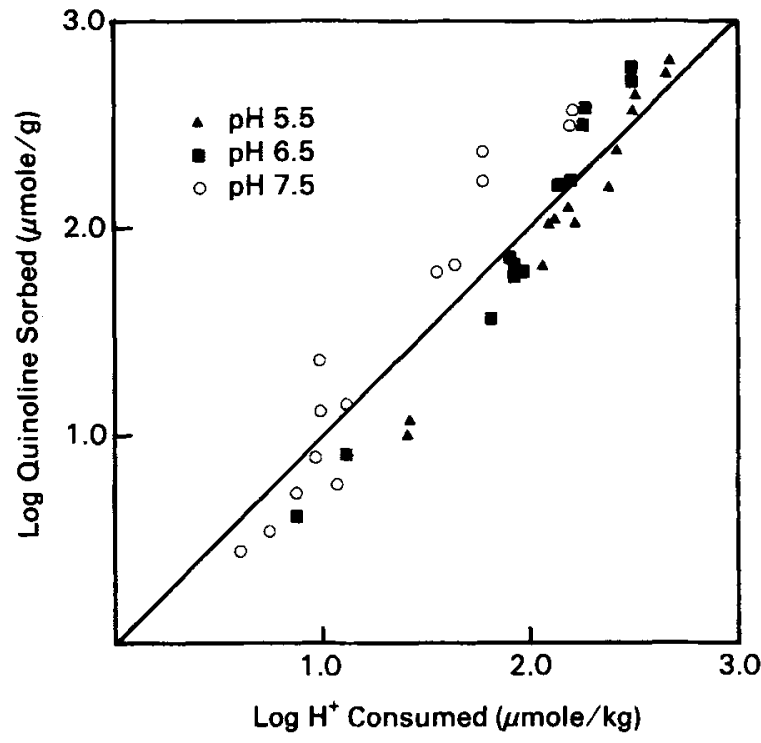

Figure 2. Hydrogen ion consumption data for the quinoline sorption isotherms at $\mathrm{pH} 7.5,6.5$, and 5.5. Diagonal line denotes one-to-one correspondence between quinoline sorbed and $\mathrm{H}^{+}$consumed.

The apparent contradiction between the sorption data in the present study and that of Doehler and Young (1961) with the results of Helmy et al. (1983) probably reflects the different surface loadings used in the individual studies. The highest quinoline concentration used in the present study was about half that of the lowest solution concentration used by Helmy et al. (1983). Consequently, different parts of the total isotherm were investigated. Qualitatively, the sum of the parts yields a complete S-type isotherm.

Concomitant with quinoline sorption is the release of hydroxyl ions. In the present study, $\mathrm{pH}$ was monitored and maintained by the addition of $0.114 \mathrm{M} \mathrm{HClO}_{4}$ so that the $\mathrm{H}^{+}$consumption could be determined over the entire concentration and $\mathrm{pH}$ range (Figure 2). The diagonal dashed line in Figure 2 represents one-to-one stoichiometry between proton consumption and quinoline sorption. The data suggest that for a given $\mathrm{pH}$ the proton consumption was about equal to the quinoline sorption, to a certain surface excess. Beyond this point, the amount of quinoline sorbed exceeded the $\mathrm{H}^{+}$consumption. The surface densities at crossover points in the titration data correlate with the break points in the isotherms (Figure 2, Table 1). The surface excess of quinoline at the crossover point for the titration data are about 10,100 , and $316(\mu \mathrm{mole} / \mathrm{g})$ for $\mathrm{pH}$ $7.5,6.5$, and 5.5 , respectively, whereas the surface excess from the intersection coordinates are 12.8, 109, and $436(\mu \mathrm{mole} / \mathrm{g})$, respectively. These findings suggest that the quinolinium ion was the dominant sorbate at low surface densities, whereas the molecular species became an important reactant at higher surface densities.

The preference for the quinolinium ion and concomitant hydroxyl release may be written as a combined protonation-exchange reaction:

$\mathrm{Q}_{\text {(aq) }}+\mathrm{H}_{2} \mathrm{O}+\mathrm{NaX}_{(\mathrm{s})}=\mathrm{QHX}_{(\mathrm{s})}+\mathrm{Na}^{+}{ }_{(\mathrm{aq})}+\mathrm{OH}^{-}{ }_{(\mathrm{aq})}$,

where $\mathrm{Q}$ denotes the neutral species; $\mathrm{NaX}$, the $\mathrm{Na}$ exchanger complex; and $\mathrm{QHX}$, the quinolinium ionexchanger complex. Although it is initially low, molecular sorption may increase at the higher surface densities and $\mathrm{pH}$ due to the formation of surface hemisalts (Mortland, 1970):

$$
\mathrm{Q}_{(\mathrm{aq})}+\mathrm{QHX}_{(\mathrm{g})}=\mathrm{X}(\mathrm{QHQ})_{(\mathrm{g})}
$$

or simple partitioning of the neutral species

$$
Q_{(a q)}=Q_{(s)}
$$

from the aqueous solution to a conditioned surface. Helmy et al. (1983) estimated that at extremely high surface loading, approximately two of every three sorbed quinoline molecules were the neutral species.

The present data suggest that quinoline sorption was dominated by cation exchange over a fairly wide $\mathrm{pH}$ and concentration range. Whether through partitioning or hemisalt formation, the onset of molecular sorption as an important contributor to the overall sorption reaction appears to have been related to solution speciation (and hence $\mathrm{pH}$ ), surface density, and solution concentration. The relationship of the sorption of the neutral species to these variables, however, is not quantitatively evident. In an attempt to substantiate the cation-exchange hypothesis and elucidate the selectivity of montmorillonite for the quinolinium cation over the $\mathrm{Na}$ cation, an exchange study was undertaken.

\section{Quinoline-Na exchange}

The analysis of the exchange data is predicated on the following assumptions: (1) the solution concentrations of neutral quinoline and the quinolinium ion $\left(\mathrm{QH}^{+}\right)$may be accurately depicted through the use of the $\mathrm{pK}_{\mathrm{a}}(4.92$, Perrin et al., 1981); (2) the activity coefficient for the neutral quinoline species is unity; and (3) the Davies equation yields an accurate description of both the $\mathrm{Na}^{+}$and $\mathrm{QH}^{+}$solution activity coefficients. The exchange reaction is depicted as:

$$
\mathrm{NaX}_{(\mathrm{s})}+\mathrm{QH}^{+}{ }_{\text {(aq) }}=\mathrm{QHX}_{(\mathrm{s})}+\mathrm{Na}^{+}{ }_{\text {(aq). }} \text {. }
$$

A conditional equilibrium constant (Vanselow convention, $\mathrm{K}_{\mathrm{v}}$ ) can be used to describe the selectivity of the exchanger phase for quinoline:

$$
\mathrm{K}_{\mathrm{v}}=\left(\mathrm{X}_{\mathrm{QH}} \mathrm{a}_{\mathrm{Na}^{+}} / \mathrm{X}_{\mathrm{Na}} \mathrm{a}_{\mathrm{QH}_{+}}\right) \mathrm{D},
$$

where $\mathrm{X}_{\mathrm{QH}}$ and $\mathrm{X}_{\mathrm{Na}}$ are the respective mole fractions on the surface, $\mathrm{D}$ is the mass of $\mathrm{H}_{2} \mathrm{O}$ in $1 \mathrm{~kg}$ of supernatant (Sposito et al., 1981), and $\mathrm{a}_{\mathrm{QH}^{+}}$and $\mathrm{a}_{\mathrm{Na}^{+}}$are the 
Table 2. Exchange data for $\mathrm{QH}^{+}-\mathrm{Na}$-montmorillonite.

\begin{tabular}{|c|c|c|c|c|c|c|c|}
\hline $\mathrm{pH}$ & $\begin{array}{c}\begin{array}{c}1 \mathrm{c}_{\mathrm{OH}} \\
\text { (mole } / \mathrm{kg})\end{array} \\
\end{array}$ & 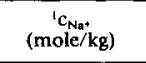 & 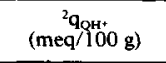 & $\begin{array}{c}{ }^{2} \mathrm{q}_{\mathrm{Nat}} \\
(\mathrm{meq} / 100 \mathrm{~g})\end{array}$ & $\begin{array}{c}{ }^{3} \mathrm{Q} \\
(\mathrm{meq} / 100 \mathrm{~g})\end{array}$ & ${ }^{4} \mathrm{~K}_{\mathrm{v}}$ & $K_{r}$ ave \\
\hline 4.95 & $3.48 \mathrm{E}-05$ & $1.07 \mathrm{E}-02$ & 43.1 & 38.9 & 82.0 & 341 & \\
\hline 4.95 & $3.52 \mathrm{E}-05$ & $1.07 \mathrm{E}-02$ & 45.6 & 40.8 & 86.4 & 340 & 341 \\
\hline 4.95 & $3.44 E-05$ & $1.06 \mathrm{E}-02$ & 45.3 & 40.8 & 86.1 & 342 & \\
\hline 4.95 & $9.61 \mathrm{E}-06$ & $9.53 \mathrm{E}-03$ & 15.1 & 57.9 & 73.0 & 259 & \\
\hline 4.95 & $1.02 \mathrm{E}-05$ & $9.05 \mathrm{E}-03$ & 15.2 & 60.6 & 75.8 & 222 & 247 \\
\hline 4.95 & $9.70 \mathrm{E}-06$ & $9.40 \mathrm{E}-03$ & 15.7 & 58.6 & 74.3 & 260 & \\
\hline 5.06 & $2.04 \mathrm{E}-06$ & $1.19 \mathrm{E}-02$ & 8.8 & 75.0 & 83.8 & 681 & \\
\hline 4.98 & $2.00 \mathrm{E}-06$ & $1.19 \mathrm{E}-02$ & 8.9 & 76.2 & 85.1 & 691 & 721 \\
\hline 5.03 & $1.91 \mathrm{E}-06$ & $1.21 \mathrm{E}-02$ & 8.9 & 71.3 & 80.2 & 792 & \\
\hline 5.07 & $5.72 \mathrm{E}-07$ & $1.10 \mathrm{E}-02$ & 4.2 & 76.2 & 80.4 & 1062 & \\
\hline 4.99 & $7.08 \mathrm{E}-07$ & $1.11 \mathrm{E}-02$ & 4.3 & 73.6 & 77.9 & 914 & 926 \\
\hline 5.02 & $6.68 \mathrm{E}-07$ & $1.11 \mathrm{E}-02$ & 4.3 & 88.8 & 93.1 & 802 & \\
\hline 4.96 & $2.03 \mathrm{E}-07$ & $1.06 \mathrm{E}-02$ & 1.7 & 70.4 & 72.1 & 1292 & \\
\hline 4.94 & $2.17 \mathrm{E}-07$ & $1.08 \mathrm{E}-02$ & 1.7 & 78.2 & 79.9 & 1099 & 1198 \\
\hline 4.87 & $2.12 \mathrm{E}-07$ & $1.09 \mathrm{E}-02$ & 1.8 & 75.3 & 77.1 & 1205 & \\
\hline 4.78 & $1.99 \mathrm{E}-07$ & $1.05 \mathrm{E}-02$ & 0.083 & 76.1 & 76.9 & 574 & \\
\hline 4.82 & $2.11 \mathrm{E}-07$ & $1.07 \mathrm{E}-02$ & 0.082 & 70.9 & 71.7 & 587 & 599 \\
\hline 4.87 & $1.87 \mathrm{E}-07$ & $1.05 \mathrm{E}-02$ & 0.083 & 73.4 & 74.2 & 638 & \\
\hline 4.91 & $4.84 \mathrm{E}-08$ & $1.05 \mathrm{E}-02$ & $7.45 \mathrm{E}-02$ & 67.2 & 67.3 & 241 & \\
\hline 4.93 & $4.73 \mathrm{E}-08$ & $1.04 E-02$ & $7.54 \mathrm{E}-02$ & 69.2 & 69.3 & 240 & 232 \\
\hline 4.93 & $4.90 \mathrm{E}-08$ & $1.03 \mathrm{E}-02$ & $7.42 \mathrm{E}-02$ & 72.4 & 72.5 & 215 & \\
\hline 4.97 & $8.34 \mathrm{E}-08$ & $1.05 \mathrm{E}-02$ & 0.015 & 85.4 & 85.6 & 228 & \\
\hline 5.10 & $7.00 \mathrm{E}-08$ & $1.04 E-02$ & 0.015 & 81.9 & 82.1 & 277 & 261 \\
\hline 5.11 & $7.57 \mathrm{E}-08$ & $1.06 \mathrm{E}-02$ & 0.015 & 77.5 & 77.7 & 278 & \\
\hline 4.75 & $4.66 \mathrm{E}-08$ & $1.03 \mathrm{E}-02$ & $7.43 \mathrm{E}-02$ & 69.3 & 69.4 & 237 & \\
\hline 4.76 & $4.91 E-08$ & $1.02 \mathrm{E}-02$ & $7.78 \mathrm{E}-02$ & 82.2 & 82.3 & 197 & 220 \\
\hline 4.75 & $4.65 E-08$ & $1.01 \mathrm{E}-02$ & $7.52 \mathrm{E}-02$ & 72.2 & 72.3 & 226 & \\
\hline
\end{tabular}

' Solution equilibrium concentration in mole per kg solution.

${ }^{2}$ Solid phase equilibrium concentration in $\mathrm{meq} / 100 \mathrm{~g}$ clay.

${ }^{3} \mathrm{Q}=\left(\mathrm{q}_{\mathrm{QH}^{+}}+\mathrm{q}_{\mathrm{Na}^{+}}\right)$expressed in meq $/ 100 \mathrm{~g}$ clay.

${ }^{4}$ Vanselow selectivity coefficient calculated using Eq. (1).

respective solution activities. The conditional equilibrium constant $\left(\mathrm{K}_{\mathrm{v}}\right)$ is related to the equilibrium constant $\left(\mathrm{K}_{\mathrm{ex}}\right)$, if the reaction is reversible, by the relationship

$$
\mathrm{K}_{\mathrm{v}}=\mathrm{K}_{\mathrm{ex}}\left(f_{\mathrm{Na}^{+}} / f_{\mathrm{QH}^{+}}\right),
$$

where the term in parentheses is the ratio of the solid phase activity coefficients.

Typically, $\mathbf{K}_{\mathrm{v}}$ is determined over the entire range of exchanger composition, with the rational solid-phase activity coefficients being calculated by integration (Sposito, 1981, Chapter 5): For the sorption considered in the present study, however, the ability to evaluate Eq. (1) to unit mole fraction, $X_{\mathrm{QH}}=1$, is at best dubious inasmuch as at high sorption densities molecular sorption has been demonstrated for related organic compounds (Karickhoff and Bailey, 1976) as well as for quinoline (Helmy et al., 1983; this study). Additionally, demixing of adsorbed inorganic and organic ions may occur at high surface densities of the organic cation (Vansant and Uytterhoeven, 1972), precluding use of solution thermodynamics to calculate solid-phase rational activity coefficients.

To circumvent this problem, the thermodynamic standard state may be defined as mole fraction 0.5
$\left(\mathrm{X}_{\mathrm{QH}}=0.5\right)$ instead of the more traditional standard state of $\mathrm{X}_{\mathrm{QH}}=1$ (Babcock and Duckart, 1980; Duckart and Babcock, 1984). Redefining the standard state in this manner does not change the expression for $\mathrm{K}_{v}$, Eq. (2); however, it does allow direct calculation of the rational activity coefficients from experimentally determined $K_{v}$ values without integration over the entire exchange isotherm. Further, $K_{e x}$ may be found directly from the $\mathrm{K}_{\mathrm{v}}$ at this standard state, $\mathrm{K}_{\mathrm{v}}{ }^{\phi}$ (Babcock and Duckart, 1980), from the relationship

$$
\mathrm{K}_{\mathrm{ex}}=\left(f_{\mathrm{QH}^{+}} / f_{\mathrm{Na}^{+}}\right) \mathrm{K}_{\mathrm{v}}{ }^{\phi}=\left(2^{\mathrm{vQH}^{+-}-\mathrm{Na}^{+}}\right) \mathrm{K}_{\mathrm{v}^{\phi}} \text {, }
$$

where $\mathrm{v}$ is the number of moles of each ion in the reaction. For the reaction considered here, $\mathrm{v}$ for both species equals one; therefore, Eq. (3) reduces to $\mathrm{K}_{\mathrm{ex}}=$ $\mathrm{K}_{\mathrm{v}}{ }^{\phi}$ when $\mathrm{X}_{\mathrm{OH}}=0.5$.

The results of the $\mathrm{QH}^{+}-\mathrm{Na}$ exchange study are summarized in Table 2. The mean normality of $\mathrm{NaClO}_{4}$ in all experiments was $0.0106 \mathrm{~N}$. The total quinoline and $\mathrm{Na}$ concentration in the solution and on the surface were determined directly, and the partitioning between the neutral and protonated solution species were calculated using $\mathrm{pK}_{\mathrm{a}}=4.92$. All quinoline removed from the surface by exchange with $\mathrm{NH}_{4}$ was considered to be the quinolinium ion. The total sorbed charge (Q) is 


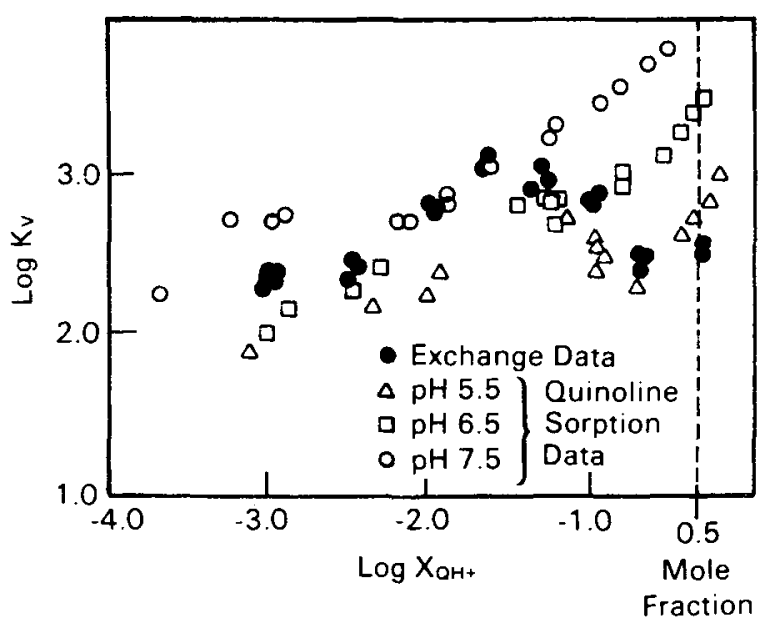

Figure 3. Data from sorption isotherm study plotted as log $\mathrm{K}_{\mathrm{v}}$ vs. $\log$ surface mole fraction $\left(\mathrm{X}_{\mathrm{QH}}\right)$, assuming all quinoline sorbed is the $\mathrm{QH}^{+}$species. Data from the exchange study are overlaid.

the sum of the sorbed $\mathrm{QH}^{+}\left(\mathrm{q}_{\mathrm{OH}^{+}}\right)$and the sorbed $\mathrm{Na}$ $\left(\mathrm{q}_{\mathrm{Na}}\right)$. The mean value of $\mathrm{Q}$ through all the experiments was $78 \pm 6 \mathrm{meq} / 100 \mathrm{~g}$. This value is below the CEC value of $86 \pm 3 \mathrm{meq} / 100 \mathrm{~g}$, at $\mathrm{pH} 5.0$, measured by ${ }^{22} \mathrm{Na}$ isotope exchange. A subset of these values at the higher mole fractions (i.e., the first 15 values in Table 2), yields a $Q$ value of $81 \pm 6 \mathrm{meq} / 100 \mathrm{~g}$, close to the measured CEC. Other reported values for the CEC of source-clay smectite SWy-1 include $92 \pm 5$ and $91 \mathrm{meq} / 100 \mathrm{~g}$ (Sposito et al., 1981; Peigneur et al., 1975, respectively).

The conditional equilibrium constant $\left(\mathrm{K}_{\mathrm{v}}\right)$ describing the exchange reaction varies from about 1200 to 350 over the exchange composition range $\mathrm{X}_{\mathrm{QH}}=0.018$ to 0.52 , with the highest $\mathrm{K}_{\mathrm{v}}$ values being observed at intermediate surface saturations (Table 2). The value of $\mathrm{K}_{\mathrm{v}}{ }^{\phi}\left(\mathrm{K}_{\mathrm{ex}}=\mathrm{K}_{\mathrm{v}}{ }^{\phi}\right.$ at $\left.\mathrm{X}_{\mathrm{QH}}=0.5\right)$ and, hence, the thermodynamic exchange constant, is 340 .

Several organic cations have been shown to sorb strongly to montmorillonite (Thompson and Brindley, 1969; Lailach et al., 1968a, 1968b; Grim et al., 1947; Dixon et al., 1970; Hayes et al., 1978). Published data, however, do not provide confirming evidence for the above $\mathrm{K}_{\mathrm{ex}}$ as a thermodynamic exchange-equilibrium constant. Theng et al. (1967) observed selectivity coefficients $\left(K_{v}\right)$ for tetraethylammonium ions on $\mathrm{Na}$ montmorillonite of about 1.58 to 22.4 at surface $\mathrm{X}_{\mathrm{Et}_{4}}$ of $\sim 0.1$ and 0.7 . In discussing his 1967 study, however, Theng (1974) concluded that without confirming evidence the $K_{e x}$ (determined from exchange isotherms over the entire range of exchanger-phase mole fraction) should best be regarded as an affinity or selectivity coefficient. He was concerned about nonreversibility and, possible, interlayer contraction, two points that have yet to be addressed adequately.
To compare the sorption isotherms and exchange isotherm data all quinoline sorbed in the former experiments (Figure 1) was assumed to be in the $\mathrm{QH}^{+}$ form and thus removed from solution via cation exchange. $\mathrm{A} \mathrm{K}_{\mathrm{v}}$ was then calculated using Eq. (1). For this calculation sorbed quinoline was taken to be the difference between the total added and that found in solution at equilibrium, and the $\mathrm{Na}$ exchanger phase concentration being set equal to the CEC minus sorbed quinoline. The clay suspension for the sorption isotherm study, although from the same source as the exchange study and prepared in the same manner, was from a different container and prepared several months later. The CEC values at $\mathrm{pH} 5.5,6.5$, and 7.5 were $100 \pm 9,103 \pm 5,105 \pm 10 \mathrm{meq} / 100 \mathrm{~g}$, respectively, as determined by ${ }^{22} \mathrm{Na}$ isotope dilution. Calculated $\mathrm{K}_{\mathrm{v}}$ values are plotted in Figure 3; the data from the exchange study are overlaid.

Conditional equilibrium constants calculated from the sorption isotherm data conform to the exchange data over a considerable range in surface densities and solution $\mathrm{pH}$ (Figure 3). Importantly, the surface excess of quinoline marking the sharp increase in $\mathrm{K}_{\mathrm{v}}$ away from that calculated from the exchange data varies with $\mathrm{pH}(17.7,100$, and $316 \mu \mathrm{mole} / \mathrm{g}$ for $\mathrm{pH} 7.5,6.5,5.5$, respectively) and is coincident with the shifts in slope of the isotherms (Table 1) and the transition in proton consumption discussed above. The similarity in selectivity coefficients calculated for the exchange and sorption (isotherm) data suggests that the quinolinium ion predominated on the surface at low aqueous concentrations over a wide $\mathrm{pH}$ range that significantly exceeded the $\mathrm{pK}_{\mathrm{a}}$.

The sharp upswing in quinoline sorption that was noted at all $\mathrm{pH}$ levels in the isotherms at the higher solution concentrations (Figure 1), and that was reflected in the departure of the $\mathrm{K}_{\mathrm{v}}$ values from the exchange data (Figure 3) suggests sorbate-assisted interactions on the montmorillonite surface. Similar phenomena have been observed for alkylated organic compounds. Cowen and White (1958) demonstrated that the adsorption isotherms for n-primary alkylammonium ions $\left(C_{3}\right.$ to $\left.C_{14}\right)$ on montmorillonite were of the Langmuir type and that sorption did not exceed the CEC for $C_{n} \leq 8$, although at $C_{n}>8$, the amount adsorbed was greater than the CEC. Chander et al. (1983), describing hemimicelle formation at the oxidewater interface, observed no hemimicelles on alumina for short-chain surfactants $\left(C_{n} \leq 8\right)$ and noted that sorption was $\log -\log$ linear. For longer chain lengths $\left(C_{n}\right.$ $>8$ ) sorption isotherms were of the S-type. The initial sorption was ascribed to monomer sorption with little if any molecular interactions, but a sharp shift in slope was described as molecular aggregation, as hemimicelles, the slope for this section of the isotherm being related to the aggregation number. If this idea is ex- 
tended to the slope shift observed in the present study, the aggregation number is about 2 . White and Cowen (1960) found considerable similarity between the extent of adsorption of octylamine $\left(\mathrm{C}_{8}\right)$ and aniline, a single benzene ring amine, on Na-montmorillonite. These results suggest that quinoline, a two-ring compound, may be similar to a long-chain alkyl compound $\left(C_{n}>8\right)$ with respect to a critical surface concentration, molecular interaction, and formation of aggregates at a solid/water interface.

\section{SUMMARY AND CONCLUSIONS}

In this paper the sorption of quinoline has been shown to increase as the $\mathrm{pH}$ of the system nears the $\mathrm{pK}_{\mathrm{a}}$ of quinoline. Exchange is an important mechanism in the adsorption of quinoline over a wide $\mathrm{pH}$ range, and the cationic form is sorbed far in excess of that indicated by the ionization fraction. The very large selectivity coefficients $\left(\mathrm{K}_{\mathrm{v}}\right)$ determined in this study underscore the importance of van der Waals interaction or entropy gains in stabilizing the surface cationic complex and the significance of cation exchange, even at very low aqueous concentrations. Bailey et al. (1968) also related retention of basic organic compounds to bulk properties of the compounds, including $\mathrm{pK}_{\mathrm{a}}$, solubility, and van der Waals interactions and to properties of the adsorbent; however, the present study has shown that above a critical concentration, significant molecular sorption of quinoline occurs. This critical surface concentration is dependent upon the $\mathrm{pH}$, surface density, and solution concentration of the neutral species in a complicated way that has not been resolved.

\section{ACKNOWLEDGMENTS}

This research was supported by the U.S. Department of Energy, Office of Health and Environmental Research, under contract DE-ACO6-76RLO 1830.

\section{LITERATURE CITED}

Babcock, K. L. and Duckart, E. C. (1980) The standard state for exchangeable cations: Soil Sci. 130, 64-67.

Babcock, K. L. and Schulz, R. K. (1970) Isotopic and conventional determination of exchangeable sodium percentage of soil in relation to plant growth: Soil Sci. 109, 19-22.

Bailey, G. W., White, J. L., and Rothberg, T. (1968) Adsorption of organic herbicides by montmorillonite: Role of $\mathrm{pH}$ and chemical character of adsorbate: Soil Sci. Soc. Amer. Proc. 32, 222-234.

Burns, I. G., Hayes, M. H. G., and Stacey, M. (1973) Some physicochemical interactions of paraquat with soil organic materials and model compounds: Weed Res. 13, 79-90.

Chander, S., Fuerstenau, D. W., and Stigter, D. (1983) On hemimicelle formation at oxide/water interfaces: in $\mathrm{Ad}$ sorption from Solution, R. H. Ottewill, C. H. Rochester, and A. L. Smith, eds., Academic Press, New York, 197210.

Cowen, C. T. and White, D. (1958) The mechanisms of exchange reactions between sodium montmorillonite and various n-primary aliphatic amine salts: Trans. Faraday Soc. 54, 691-697.

Dixon, J. B., Moore, D. E., Agnihotri, N. P., and Lewis, D. E., Jr. (1970) Exchange of diquat ${ }^{2+}$ in soil clays, vermiculite, and smectite: Soil Sci. Soc. Amer. Proc. 34, 805-808.

Doehler, R. W. and Young, W. A. (1961) Some conditions affecting the adsorption of quinoline by clay minerals in aqueous suspensions: in Clays and Clay Minerals, Proc. 9th Natl. Conf., West Lafayette, Indiana, 1960, Ada Swineford, ed., Pergamon Press, New York, 468-483.

Duckart, E. C. and Babcock, K. L. (1984) Thermodynamics of cation exchange using Babcock's standard state: Soil Sci. 138, $1-7$

Gilmour, J. T. and Coleman, N. T. (1971) s-Triazine adsorption studies: Ca-H-humic acid: Soil Sci. Soc. Amer. Proc. 35, 256-259.

Grim, R. E., Allaway, W. H., and Cuthbert, F. L. (1947) Reaction of different clay minerals with some organic cations: J. Amer. Chem. Soc. 30, 137-142.

Hayes, M. H. B., Pick, M. E., and Toms, B. A. (1978) The influence of organocation structure on the adsorption of mono- and of bipridinium cations by expanding lattice clay minerals. I. Adsorption by $\mathrm{Na}^{+}$-montmorillonite: $J$. Colloid Interface Sci. 65, 254-265.

Helmy, A. K., De Bussetti, S. G., and Ferreiro, E. A. (1983) Adsorption of quinoline from aqueous solutions by some clays and oxides: Clays \& Clay Minerals 31, 29-36.

Karickhoff, S. W. and Bailey, G. W. (1976) Protonation of organic bases in clay-water systems: Clays \& Clay Minerals 24, 170-176.

Lailach, G. E., Thompson, T. D., and Brindley, G. W. (1968a) Absorption of pyrimidines, purines, and nucleosides by $\mathrm{Li}$-, $\mathrm{Na}-, \mathrm{Mg}$-, and $\mathrm{Ca}-$ montmorillonite (clay-organic studies XII): Clays \& Clay Minerals 16, 285-293.

Lailach, G. E., Thompson, T. D., and Brindley, G. W. (1968b) Absorption of pyrimidines, purines, and nucleosides by $\mathrm{Co}-, \mathrm{Ni}-, \mathrm{Cu}$-, and $\mathrm{Fe}$ (III)-montmorillonite (clayorganic studies XIII): Clays \& Clay Minerals 16, 295-301.

Moreale, A. and Van Bladel, R. (1976) Influence of soil properties on adsorption of pesticide-derived aniline and p-chloroaniline: $J$. Soil Sci. 27, 48-57.

Mortland, M. M. (1970) Clay-organic complexes and interactions: Adv. Agron. 22, 75-117.

Peigneur, R., Maes, A., and Cremers, A. (1975) Heterogeneity of charge distribution in montmorillonite as inferred from cobalt adsorption: Clays \& Clay Minerals 23, 71-75.

Perrin, D. D., Dempsey, B., and Serjeant, E. P. (1981) $p K_{a}$ Prediction for Organic Acids and Bases: Chapman and Hall, New York, 146 pp.

Philen, O. D., Jr., Weed, S. B., and Weber, J. B. (1970) Estimation of surface charge density of mica and vermiculite by competitive adsorption of diquat ${ }^{2+}$ vs. paraquat ${ }^{2+}$ : Soil Sci. Soc. Amer. Proc. 34, 527-531.

Sposito, G. (1981) The Thermodynamics of Soil Solutions: Oxford University Press, New York, 223 pp.

Sposito, G. (1984) The Surface Chemistry of Soils: Oxford University Press, New York, 234 pp.

Sposito, G., Holtzclaw, K. M., Johnston, C. T., and LeVesqueMadore, C. S. (1981) Thermodynamics of sodium-copper exchange on Wyoming bentonite at $298^{\circ} \mathrm{K}$ : Soil Sci. Soc. Amer. J. 45, 1079-1084.

Theng, B. K. G. (1974) The Chemistry of Clay-Organic Reactions: Wiley, New York, 221-319.

Theng, B. K. G., Greenland, D. J., and Quirk, J. P. (1967) Adsorption of alkylammonium cations by montmorillonite: Clay Miner. 7, 1-17.

Thompson, T. D. and Brindley, G. W. (1969) Adsorption of pyrimidines, purines and nucleosides by $\mathrm{Na}-, \mathrm{Mg}-$, and 
$\mathrm{Cu}(\mathrm{II})$-illite (clay-organic studies XVI): Amer. Miner. 54, 858-868.

Vansant, E. F. and Uytterhoeven, J. B. (1972) Thermodynamics of exchange of n-alkylammonium ions on $\mathrm{Na}$ montmorillonite: Clays \& Clay Minerals 20, 47-54.

White, D. and Cowen, C. T. (1960) Aromatic amine derivatives of montmorillonite: Brit. Ceram. Soc. 59, 16-21.

Weed, S. B. and Weber, J. B. (1969) The effect of cation exchange capacity on the retention of diquat ${ }^{2+}$ and paraquat ${ }^{2+}$ by three-layer type clay minerals. I. Adsorption and release: Soil Sci. Soc. Amer. Proc. 33, 379-385.
Zachara, J. M., Ainsworth, C. C., Felice, L. J., and Resch, C. T. (1986) Quinoline sorption to subsurface materials: Role of $\mathrm{pH}$ and retention of the organic cation: Environ. Sci. Technol. 20, 620-627.

Zierath, D. L., Hassett, J. J., Banwart, W. L., Wood, S. G. and Means, J. C. (1980) Sorption of benzidine by sediments and soils: Soil Sci. 129, 277-281.

(Received 27 August 1986; accepted 13 December 1986; Ms. 1607) 